\title{
Study on the Guidance and Governance of Network Public Opinion in Public Emergencies
}

\author{
Yuling Liu \\ Shaanxi Institute of International Trade \& Commerce, Xi'an, Shaanxi, 710046
}

\begin{abstract}
Keywords: Network Public Opinion, Public Emergencies, Guidance and Governance
\end{abstract}
\begin{abstract}
With the development of the international situation and the continuous improvement of socialism with Chinese characteristics, combined with the strong arrival of the Internet-based new media, the outbreak of public emergencies, the development of fast, rich, free to spread and report, So as to bring timely information to the people at the same time because of some of the network because of public opinion on the negligence of the management and reporting to the very state of society to bring greater damage. So the effective guidance of public emergencies in the network public opinion is to prevent the deterioration of the fundamental, but also the premise of dealing with such incidents. This article is from how to effectively guide this point of view, the public emergencies in the network public opinion of the government guidance mechanism in-depth study.
\end{abstract}

\section{Introduction}

At present, the network has often become a platform to participate in social public affairs and express the demands of the audience, and has become an important carrier of public opinion because of its high speed of communication, large area of influence, wide range of influence and small input cost. The open and multidimensional communication channel of the network provides the public with free information and information sharing. The application of the network changes the citizen's weak position in the process of information transmission, and every citizen may become the publisher of the information. The public through the network concerned about social issues, comments, communication and discussion. In this process, the network public opinion for the government to develop a policy to provide a realistic basis, has become a useful complement to the supervision of social public opinion, while its social decompression function is more social contradictions to play a catalytic role. But the popularity of the network also brings its negative side, the network virtualization can easily lead to the network of the main responsibility of the virtual, easily lead to the occurrence of irrational behavior. The network is easy to provoke, easy to be implied, and the network anonymity characteristics and easy to lead to network speech intensified, emotional, these characteristics have led to the network easily become negative emotions, extreme behavior of the hotbed. At the same time, China is in the process of economic transformation, social transition, all kinds of social contradictions, unstable factors, people urgently need to express their views, the interests of the demands of the channels, but the reality of social citizens expressed and appeal less channels In the event of public emergencies, the network happens to be a place where people freely express their opinions and vent their emotions. However, if there is a lack of effective supervision and guidance in this process, people are dissatisfied with the discussion of some social problems. The process of communication continue to gather, exaggerate, and even may appear on the original event of misunderstanding and misunderstanding, when these reality and social dissatisfaction with the accumulation of certain limits, it may lead to the outbreak of the network public opinion crisis. Therefore, in view of the strong influence of the public opinion of the network, the research on the government guidance mechanism of public opinion in the public emergencies has been paid more and more attention by many experts and scholars. But also become the current government at all levels need to solve the real problem, but also at all levels of government is facing a major issue and serious challenges. 


\section{The Concept of Public Emergencies}

"Public emergencies," the word, I believe in the last century version of the word can not be found in the sea, it is accompanied by the continuous development of social transformation of birth, as an objective phenomenon gradually deep into the minds of the people. Initially, people simply described the "public outburst" (which took place) with "events" (what was happening in society), but it was far from what it meant. International public emergencies are generally defined as "a special, imminent crisis or dangerous situation that affects all citizens and pose a threat to the normal life of society as a whole". This is a more representative definition. The concept of public emergencies in the country is to define the different areas of experts and scholars have different views and views. Some scholars believe that public emergencies are a comprehensive call, including all unexpected events. Public emergencies can cover many areas, such as natural disasters, serious traffic accidents. The concept of public emergencies is not precise, it is only a convention, the concept of time extension is also very narrow, because the public emergencies for the impact of the whole society continued a process, and may have far-reaching impact. To this end, the "People's Republic of China Incident Response Law" (the twentieth session of the Standing Committee of the twentieth session of the Standing Committee in August 2007 adopted) to make a unified clear definition of "public emergencies, Sudden occurrence, natural disasters, accidents, public health events and social security incidents that cause or may cause serious social harm and require urgent action to be addressed ". It can be said that public emergencies mean that the normal social order of the sudden problems, mass life, collective or personal property is facing a serious threat, the need for social management system the first time to respond, make decisive and effective decision-making, the largest Limit the loss of the loss, return to normal order.

\section{The Current Situation of Public Opinion in Public Emergencies}

The existing public emergencies in the network public opinion guidance mechanism to run the mechanism to play well, can not effectively coordinate the government, the media and the interests of the public relations. The government can not act in a timely manner when it encounters public emergencies, can not communicate effectively with the mainstream media to ensure that the correct information is objectively reported and can not guide and direct the public in the direction of expectation in real time. The existing public emergencies in the network public opinion guidance mechanism to induce the mechanism and educational mechanism to play smoothly, the government can not be well coordinated with the media, the first time to report the development of the situation, as well as the public education is not enough, not in Public emergencies in the network public opinion occurs when the overall situation of the whole society to effectively grasp and correct guidance. The existing public emergencies in the network public opinion guidance mechanism to deal with adverse mechanisms, due to coping style and method of defective is not conducive to effectively guide the public emergencies in the network public opinion.

The existing public emergencies in the network public opinion guidance mechanism in the process of running do not pay attention to long-term, coordination and interaction issues. The existence of a mechanism is not static, it is with the changes in time, the development of the surrounding environment and constantly updated, added, progress, which requires the existence of the mechanism is the need to keep the vitality of the continuous improvement of their own. The normal operation of the mechanism but also to coordinate the interests of all parties, so that all the material, human and financial resources are organically together to jointly promote the effective operation of the mechanism. For the public emergencies in the network public opinion guidance mechanism, but also to deal with the government, the media, the relationship between the public, to enable the government and the media to communicate effectively, to enable the government and the public to effectively interact, thus So that public emergencies in the network public opinion has been effectively controlled. 


\section{The Design of the Guiding Mechanism of Network Public Opinion in Public Emergencies}

Public guidance in the network of public opinion to guide the problem is a very complex issue. It brings harm and its social control is both related to theoretical issues, but also related to practical problems. The development of public opinion on the network, if not controlled, can cause unpredictable serious consequences. Control is too strict, but also reduces the free speech of Internet users, which is contrary to the purpose of the network. Therefore, for public emergencies in the network public opinion to guide the problem, as the government regulators must pay attention to grasp the degree, to master the public in the event of public opinion and network information freedom between how to maintain the necessary tension. Government monitoring system for people's monitoring and information collection should be controlled within the limits of non-infringement of privacy, so as to effectively guide the community.

In the contemporary society, the news media, in the government and various social forces, to ease the social tension, plays a special and important role in the media. Guide the public emergencies in the process of public opinion, the government and public information communication is smooth, the rapid and accurate media communication information will make the public face public emergencies to keep the reason, so as to solve the event to create a good social psychological atmosphere. Mainstream media quickly involved in public attention is extremely high public emergencies, is to eliminate perjury, put aside panic, to curb rumors of the most effective means. The media should be in the public service, the benefit of the community's public responsibility, with a rational attitude and objective remarks timely and accurate coverage, publish information, guide public opinion, to appease public sentiment, to maintain social stability.

Public emergencies in the network public opinion guide, the public are very important part of the link. It is the responsibility of the media, the responsibility of the society and the responsibility of the public themselves to cultivate the public's discrimination and judgment on various information, especially the network information. Only by vigorously developing cultural and educational education, pay close attention to the quality of the people and improve the public's ability to judge the public opinion in order to be able to distinguish between right and wrong in the face of public emergencies, and to confuse the rumors without blindness, Difficult to lay a solid foundation. We should do the public education and grooming work as the most important and most prominent task. The majority of netizens as citizens should have a sense of citizenship, that is, the need to establish a citizen and the state between the rights and obligations. Constitution gives citizens the basic rights, but also provides the basic obligations of citizens, citizens should exercise their rights properly, consciously fulfill their obligations. In the online world, to enhance the sense of civic responsibility, improve network moral quality.

Now, after the occurrence of public emergencies, all kinds of rumors will appear in different forms on the Internet, this phenomenon is not only contrary to the spirit of law, but also endangering public safety, so the urgent need to correct the relevant laws. According to the law to investigate and punish the communicators of the incident, to maintain the health and safety of Internet information, is the basic requirements of the rule of law society, but also the eagerly look forward to the majority of Internet users. So the relevant departments to public emergencies network public opinion guidance mechanism management as a long-term task to grasp.

\section{Conclusion}

The incidence of public emergencies in China and the degree of damage are constantly intensified, seriously affecting the stability of social order, to bring great pain to the public. At the same time, the new media to the Internet as an example of the extensive use of its convenience, freedom and other characteristics of the public by the general pro-Lai. This has led to a complex chemical reaction in the event of public emergencies, so that the severe public emergencies are more difficult to control and respond to. Therefore, with the development of the international situation and the continuous improvement of socialism with Chinese characteristics, in order to actively control the situation of sustained deterioration, this article choose from the effective public emergency events 
in the network public opinion point of view, in-depth study, designed a public The government guidance mechanism of public opinion in emergencies is aimed at alleviating the existing problems of existing mechanisms.

\section{References}

[1] Li Zhaocui. Study on the propaganda and early warning model of public opinion in emergencies [J].Computer and telecommunications, 2016 (10)

[2] Hou Xiangyi. From the media age background, how should the government control network public opinion [J]. Audio-visual, 2017 (03)

[3] Chu Xiaoqing, Wang Naixin. Network public opinion supervision of the problems and countermeasures [J]. Theory, 2016 (11)

[4] Liu Xinrong. To enhance the civil service network public opinion response ability [J]. Theory, 2015 (34)

[5] Wang Pengbing. Social transition period network public opinion and its governance theory [J]. Journal of the Party School of CPC Jinan Municipal Committee, 2015 (06)

[6] Chen Wei. Strengthening China's network public opinion governance legal regulation [J]. China Information Security, 2016 (03) 